Earth Interactions - Volume 12 (2008) - Paper No. 10 • Page 1

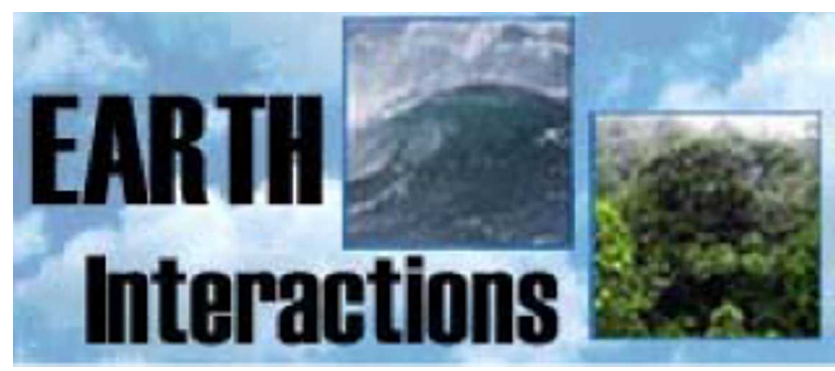

Paper 12-010; 3,871 words, 4 Figures, 0 Animations, 0 Tables.

http://EarthInteractions.org

\title{
Interannual Variability of Sea Surface Height over the Black Sea: Relation to Climatic Patterns
}

\section{A. Birol Kara,* Charlie N. Barron, and Alan J. Wallcraft}

Oceanography Division, Naval Research Laboratory, Stennis Space Center, Mississippi

\section{Temel Oguz}

Institute of Marine Sciences, Middle East Technical University, Erdemli, Icel, Turkey

Received 18 January 2008; accepted 3 June 2008

\begin{abstract}
Sea surface height ( $\mathrm{SSH})$ variability is presented over the Black Sea during 1993-2005. The $1 / 4^{\circ} \times 1 / 4^{\circ}$ resolution daily SSH fields are formed using optimal interpolation of available altimeter data. SSH variability reveals distinct maxima in the eastern and western basins, reflecting variations in the corresponding gyres. A joint examination of SSH and sea surface temperature (SST) indicates strong relationship between the two only in winter, with correlations as high as 0.6 or more. This would reflect a steric change in sea surface height due to thermal expansion averaged over a relatively deep winter mixed layer. Newly developed SSH fields also demonstrate a switch to the positive mode of SSH starting from the end of 1996 lasting $\approx 4 \mathrm{yr}$. Such a climatic shift is found to be strongly related to large-scale teleconnection patterns. Finally, the daily SSH and SST anomaly fields presented in this paper can supplement various applications in the Black Sea, such as examination of biological production and mesoscale eddy dynamics.
\end{abstract}

KEYWORDS: Sea surface height (SSH); Black Sea; Altimeter

* Corresponding author address: Dr. A. Birol Kara, Naval Research Laboratory, Oceanography Division, Code 7320, Bldg. 1009, Stennis Space Center, MS 39529.

E-mail address: birol.kara@nrlssc.navy.mil 
Earth Interactions - Volume 12 (2008) • Paper No. 10 - Page 2

\section{Introduction}

Analysis of interannual sea surface height (SSH) variability and identification of the impact of regional and global factors is of great interest for understanding climatic changes in the Black Sea, involving its basin dynamics and ecosystem. SSH can be used for interpreting subsurface temperature and salinity variability, which is generally difficult to obtain at fine spatial and temporal scales for an ocean basin (e.g., Mayer et al. 2001).

SSH variability includes steric and nonsteric signals, elevation changes due to changing vertically integrated specific volume anomaly at constant mass and elevation changes due to changing mass per unit area. Steric SSH signals should be correlated with SST unless the change resulted from variations in thermocline or mixed layer depth. One important factor is to determine whether sea level variations are mainly caused by steric variations due to the heat and salt exchanges between the atmosphere and ocean, the internal ocean dynamics, etc., in addition to large-scale teleconnection patterns, which are important factors in the Black Sea (Oguz and Gilbert 2007).

Our effort in this study is to focus on the steric component of SSH variability. Rather than relating the mean SSH to prevalent circulation patterns, we focus on SSH variations, examining the degree to which SSH and SST independently characterize Black Sea variability. This paper considers the most recent time period, a 13-yr series from 1993 through 2005 (section 2), providing a more recent context for interpreting climate patterns with a particular focus on the existence of seasonal steric SSH signals (section 3). SSH anomaly fields are further used for investigating role of large-scale atmospheric teleconnection patterns over the Black Sea (section 4).

\section{Altimeter-based SSH}

\section{1. Data processing}

The dataset for SSH is obtained from the altimeter products prepared by the operational real-time U.S. Navy Altimeter Processing System (ALPS; available online at http://www7300.nrlssc.navy.mil/altimetry). Altimeter data follow different pathways before entering the ALPS at the U.S. Naval Oceanographic Office (NAVOCEANO). The Geosat Follow-On (GFO) satellite data is sent directly to the Payload Operation Center (POC) at NAVOCEANO. Orbit solutions are produced by both the Naval Satellite Operations Center (NAVSOC) and at the Jet Propulsion Laboratory (JPL) based on the global positioning system receivers on board the satellite.

Ocean Topography Experiment (TOPEX) data was retrieved from a NAVOCEANO computer within the datastream at JPL where it was converted from the raw satellite telemetry data into physical units. The data and JPLproduced orbit solutions were then passed on to the Altimetry Data Fusion Center (ADFC) at NAVOCEANO. The (European Remote Sensing Satellite) ERS-2 data are provided by the European Space Agency (ESA) through the National Oceanic and Atmospheric Administration (NOAA) Laboratory for Satellite Altimetry.

Data processing for each above-mentioned altimeter is accomplished through 
Earth Interactions - Volume 12 (2008) • Paper No. 10 • Page 3

five steps: 1) initial data processing, 2) interpolation, 3) tide removal, 4) orbit error removal, and 5) referencing to a consistent mean. All of these steps are discussed in detail in the ALPS mentioned earlier, so they are not repeated here. However, we will provide a general overview of the various geophysical corrections in the initial processing of altimeter data.

Altimeters emit microwave signals that are reflected from the ocean surface. The two-way travel time of the signal can be converted by a distance between the satellite and ocean surface if the speed of light in the atmosphere is accurately known. The dry troposphere path delay, wet troposphere path delay, ionosphere path delay, and electromagnetic bias correction terms all enable a more accurate estimate of the signal speed and thus a more accurate distance between the altimeter and sea surface.

The distance between the altimeter and sea surface is the first element in measuring SSH. The second element is an accurate determination of the position of the altimeter relative to the local geoid. This orbit solution is one of the largest error sources associated with real-time altimeter data. To minimize this error, the navy Generalized Digital Environmental Model (GDEM) is used. This model based on climatological bathythermograph data allows us to maintain the seasonal steric signal in the SSH data while removing orbit errors. Orbit error removal is done on one satellite revolution's worth of data at a time using a weighted least squares technique with weighting based on the variability observed by prior altimeter missions. This minimizes the impact of large-amplitude features in the areas dominated by mesoscale variability.

\subsection{Altimeter data in the Black Sea}

Daily reanalysis of $\mathrm{SSH}$ is constructed using all available satellite altimeter data for the Black Sea from the beginning of 1993 to the end of 2005. The dataset for $\mathrm{SSH}$ is obtained from ALPS. The data retrievals from ALPS provide an SSH deviation from the multiannual mean SSH at each ground-track location (Jacobs et al. 2002). The ground tracks of the altimeters are shown in Figure 1a. There are 10-day orbits for TOPEX/Poseidon (T/P; January 1993-August 2002) and Jason-1 (March 2002-December 2005), a 17-day orbit for GFO (December 2000December 2005), and 35-day orbits for the ERS/Envisat satellites (January 1995December 2005).

The data retrievals from ALPS provide Modular Ocean Data Assimilation System (MODAS) an SSH deviation from the multiannual mean SSH at each ground-track location; $\mathrm{SSH}_{\text {altimeter }}=$ altimeter measurement $-<$ altimeter measurement $\rangle_{\text {alt }}$, where " \langle\rangle$_{\text {alt }}$ " refers to an averaging over the multiyear altimeter data collection period from 1993 through 2001 (Jacobs et al. 2002). Crossover points are used to reference the altimeter data to a common TOPEX mean (Zlotnicki et al. 1989). The altimeter provides an anomaly from a long-term mean, so a mean SSH must be added from another source to form the full SSH.

Spatial gaps between the ground tracks are fairly wide relative to a small, enclosed region like the Black Sea. The space-time interpolation must try to represent along-track detail while minimizing spurious features in the data voids. This is accomplished using MODAS2D optimal interpolation with a spatially variable error covariance determined from analysis of long altimeter time series 
(a) Altimeter tracks during 1993-2005
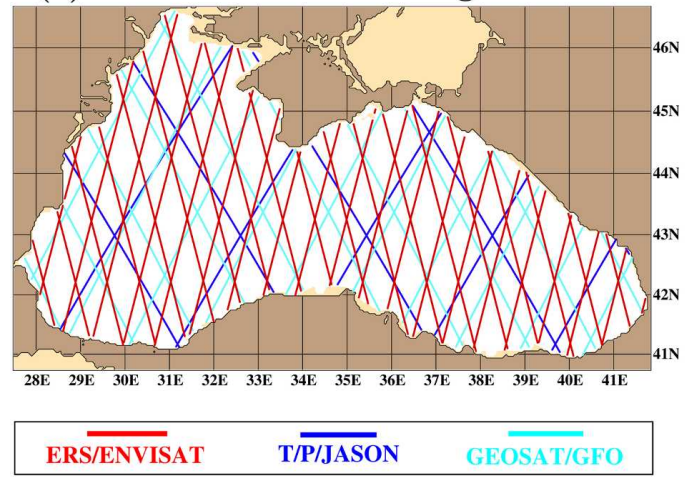

(c) SSH anomaly $(\mathrm{cm})$ : the Black Sea

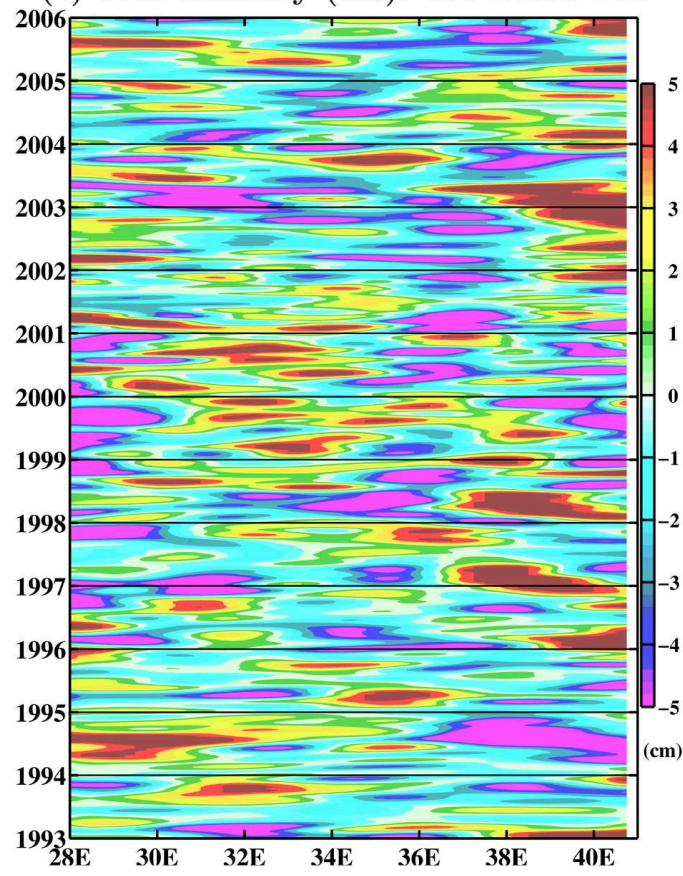

(b) Standard deviation of SSH (cm)

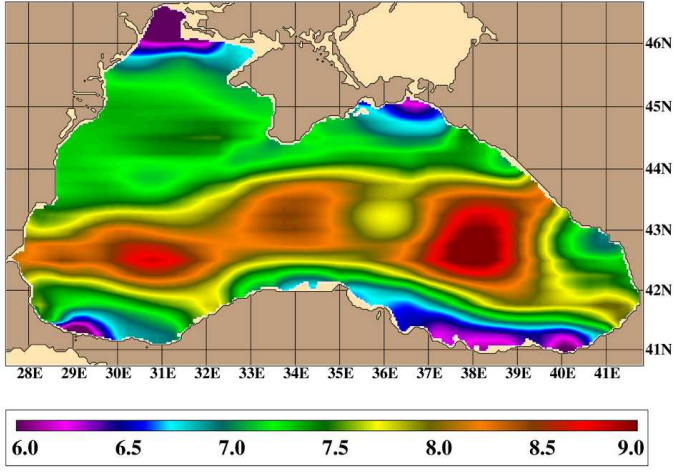

(d) SSH anomaly (cm): Central Pacific

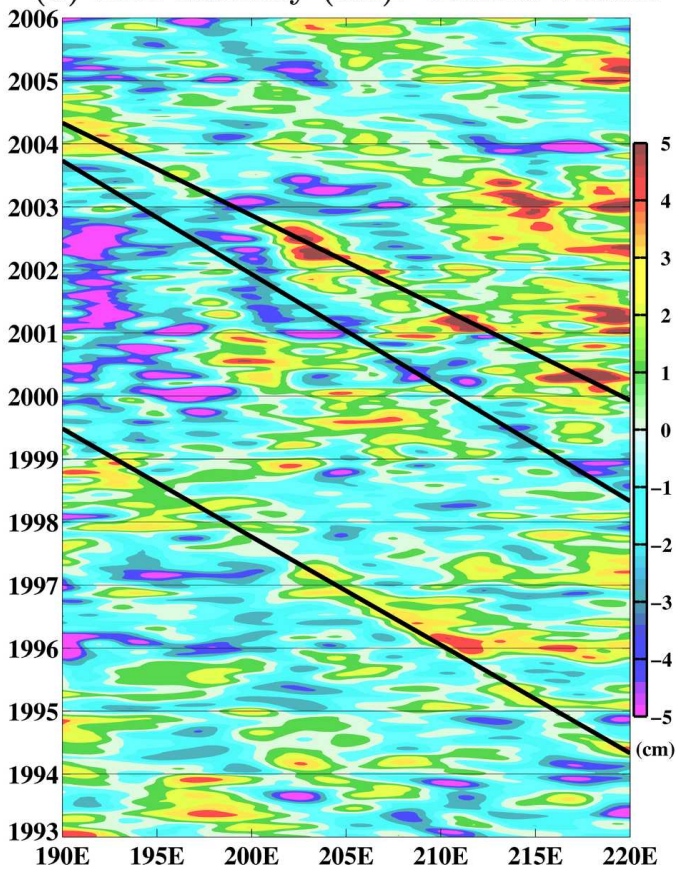

Figure 1. (a) Repeating ground tracks of three altimeters (ERS/Envisat in red, T/P and Jason- 1 in blue, and Geosat/GFO in cyan) over the Black Sea from 1993 through 2005. (b) SSH standard deviation during 1993-2005. (c) Longitudetime sections of monthly mean SSH anomaly at $43^{\circ} \mathrm{N}$ in the Black Sea. No significant slope is evident. (d) The same as (c), but for the central Pacific Ocean. Mean slope for all solid black lines is $\approx 1.6 \mathrm{~cm} \mathrm{~s}^{-1}$.

(Jacobs et al. 2002). The first guess in the optimal interpolation is an average of the SSH observations using a Gaussian weighting with $750-\mathrm{km}$ zonal, $250-\mathrm{km}$ meridional, and 15-day temporal scales, all of which were chosen subjectively after some tests. The global MODAS2D analysis excludes all altimeter observations shallower than $200 \mathrm{~m}$, because the nonsteric contributions to SSH in shallower regions typically exceed limits imposed by downstream applications. We 
Earth Interactions - Volume 12 (2008) - Paper No. 10 - Page 5

use the data to calculate 1993-2005 mean values for each month of the year, which are used to calculate individual monthly anomalies.

\section{Sea level variability in the Black Sea}

Evaluation of SSH time series over 1993-2005 yields SSH standard deviations $(>8 \mathrm{~cm})$ in the interior (Figure $1 \mathrm{~b})$. The relatively small values in shallow regions are ignored as a consequence of excluding shallow observations in the data processing. The maxima in SSH variability indicate centers of the eastern and western gyres. The larger SSH variability in the east indicates greater variation in the circulation of the eastern gyre.

Longitude-time plots of SSH anomalies are examined to identify westward propagation of Rossby waves in the Black Sea (Figure 1c). The time series samples a zonal section at $43^{\circ} \mathrm{N}$, where water is typically deep $(>1500 \mathrm{~m})$ in the interior. The data were processed to make the zonally averaged SSH zero at each time step. Unlike the study by Korotaev et al. (Korotaev et al. 2003), we are not able to unambiguously identify westward-propagating waves in the Black Sea. It must be emphasized that the waves appear in the Black Sea, but not quite clearly, as diagonal (i.e., going from bottom right to top left) alignments of crests and troughs. The speed at which waves propagate in the longitude-time plot is given by the slope of the alignments of crests and troughs. The propagation signatures are almost ubiquitous. More than one speed is noted. This is likely to reflect a number of different modes of Rossby waves propagating at different speeds. Furthermore, speed of propagation tends to increase westward across the Black Sea, which is consistent with linear theory.

For comparisons with waves in the Black Sea, we investigate the westward propagation in the central North Pacific over the same latitude and time period (Figure 1d). Rossby waves are more easily identified in the central North Pacific since it is isolated from coastal or boundary current influences; in contrast, Rossby waves are difficult to distinguish in the Black Sea because of its smaller, enclosed domain and strong boundary influences.

We now examine the distribution of seasonal and interannual variability of $\mathrm{SSH}$ from 1993 through 2005. Monthly mean SSH anomalies are formed (Figure 2). In general, SSH interannual variability in the Black Sea is between -10 and $10 \mathrm{~cm}$, as evident during most months. There is a switch to the positive mode of SSH anomaly at the end of 1996 lasting up to 2002 except for a few months. This may correspond to large-scale teleconnection patterns, noted in many properties of the Black Sea. This topic was discussed with respect to climatological indicators in Oguz et al. (Oguz et al. 2006) and will be further explored in section 4.

While there is a climatological seasonal steric SSH signal, this is removed by considering anomalies from the means of each month of the year. Our hypothesis is that the remaining SSH variability is largely a steric response to changes in heating and/or salinity stratification. These changes in stratification will largely be above the seasonal thermocline. To the extent that the steric signal is from mixed layer temperature, SST can be considered a good proxy for SSH. Thus, investigating possible links between SST and SSH variability allows us to determine whether SSH variability is largely a steric response to changes in heating processes. On the other hand, the Black Sea mixed layer can be very shallow (a few 
meters) in the summer (e.g., Kara et al. 2005), and SST anomaly may then be a poor representation of subsurface temperature anomaly.

To test the above-mentioned hypothesis, in addition to $\mathrm{SSH}$, we also form daily SST anomalies from MODAS during 1993-2005. Each daily MODAS SST is produced by an optimal interpolation (OI) of Advanced Very High Resolution Radiometer (AVHRR) observations, using a methodology described in Barron and Kara (Barron and Kara 2006). The resulting monthly SST anomaly does not show the same trend as the SSH anomaly (Figures 3a and 3b), and it has significantly more month-to-month variability than the SSH anomaly.

It may appear that there is a slowly increasing trend in SSH during 1995-2005 but a least squares fit to 1997-2005, for example, would slope the other direction, that is, decreasing trend. Thus, the linear trend is not very robust for SSH variability. This is partly because the interannual SSH anomalies are much smaller than the average seasonal signal during 1993-2005. However, unlike a possible linear increase or decrease in time, there is a cyclic trend in $\mathrm{SSH}$, as shown by the dark solid curve in Figure 3a. While a more sophisticated approach involving sinusoidal terms to account for cyclic effects would be a better approach for trend analysis, this is beyond the focus of this paper.

SST and SSH fields are generally not well related to each other since the correlation based on monthly mean time series is very low with a value 0.21 during 1993-2005. To examine seasonal dependence, monthly mean SST and SSH anomalies in each season are grouped, yielding a time series of 39 monthly mean values at each $1 / 4^{\circ} \times 1 / 4^{\circ}$ grid box in the Black Sea for winter, spring, summer, and fall during 1993-2005. Linear correlations are then calculated at each grid and mapped over the Black Sea. Correlations are compared within each season to demonstrate that, while overall correlation between SSH and SST may be low, it varies seasonally (Figure 3c).

The strong relationship between SST and SSH is significant only in the winter, and high correlations typically exist in the interior of the Black Sea. These winter correlations would correspond with periods of a relatively deep mixed layer. If the mixed layer is deep, then SST represents a larger fraction of the water column and a vertically integrated volume anomaly. Thus, SSH anomalies are responding to nonsteric and subsurface steric changes in addition to surface heating and cooling in the Black Sea.

Based on the statistical significance test in comparison to zero, an absolute correlation value of at least 0.31 is needed at the $95 \%(\alpha=0.05)$ confidence level based on 39 monthly mean time series. Therefore, SSH and SST variations are not significantly related to each other for the majority of the Black Sea in seasons other than winter. Given this strong relationship, we conclude that at least some of the winter SSH anomaly is steric because of temperature changes in the deep mixed layer. Even in winter, correlations are highest in the interior of the basin and are particularly low near river mouths, the Kerch Strait (the Sea of Azov), and the Bosporus Strait (the Marmara Sea), that is, in regions where salinity variability would be expected to have a relatively larger effect on $\mathrm{SSH}$.

Analysis of interannual anomalies SSH and SST could be extended to include anomalies of the river runoff and/or wind stress curl and climate indices. A detailed consideration of these is beyond the scope of this paper. River runoff would likely be more significant locally than over the entire Black Sea. Studies of 
(a) Monthly mean SSH anomaly (cm)

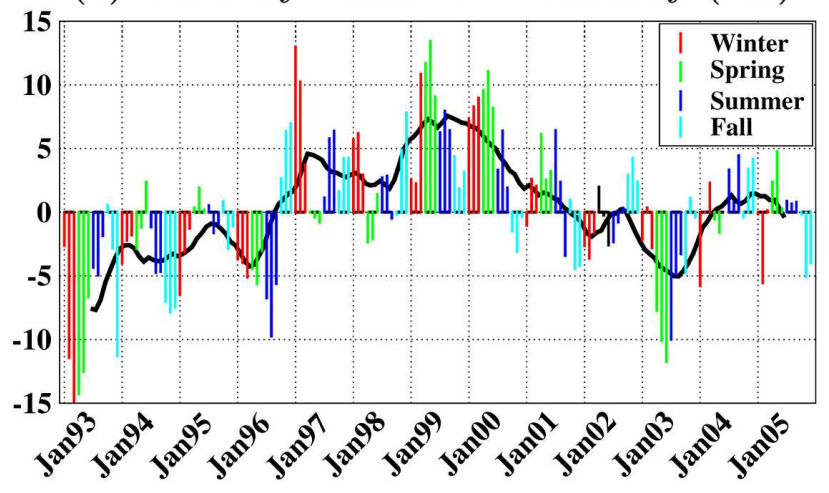

(b) Monthly mean SST anomaly $\left({ }^{\circ} \mathrm{C}\right)$

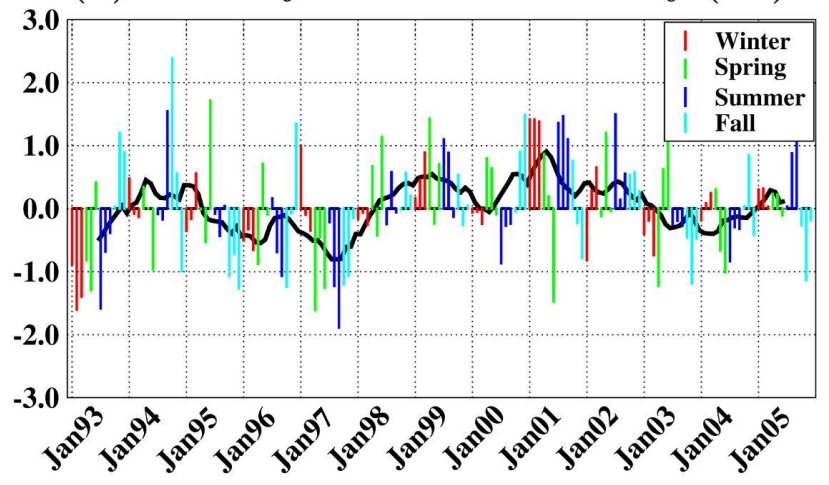

(c) Correlation of SST vs SSH anomaly Winter Spring
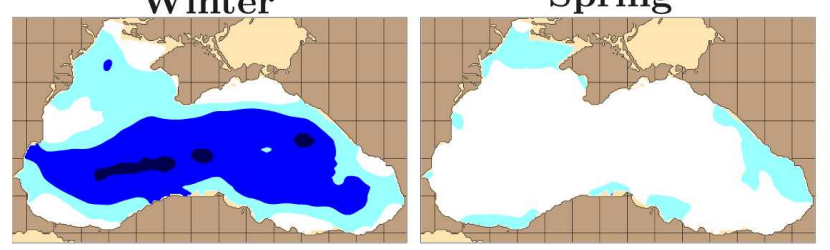

Summer

Fall

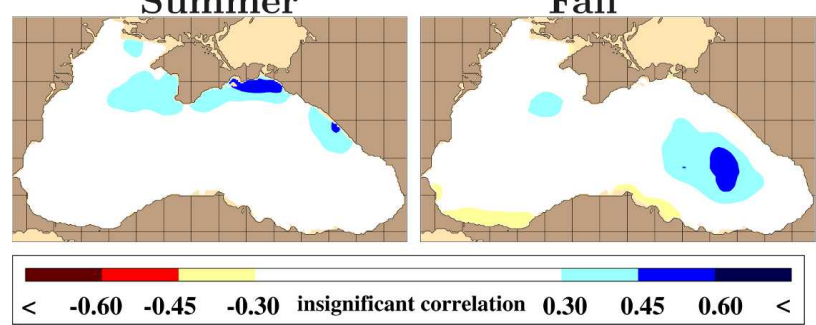

Figure 3. (a) Monthly means of basin-averaged satellite-based (a) SSH and (b) SST anomalies over the Black Sea from 1993 through 2005. Spatial variation of linear correlation coefficient between SSH and SST is given in (c) by season during 1993-2005. We follow Locarnini et al. (Locarnini et al. 2006) in our definition of the Northern Hemisphere seasons: January, February, and March (winter); April, May, and June (spring); July, August, and September (summer); October, November, and December (fall). 
Earth Interactions - Volume 12 (2008) - Paper No. 10 • Page 9

wind stress curl that relied on archives of global NWP products might not have sufficient resolution over the small area, and the short time series from 1993-2005 might be insufficient to support conclusions on the relation between climate indices and Black Sea SSH.

\section{Sea level variability in relation to climate indices}

Concerning the results shown in Figure 2, one particular question arises here: Can the shift in the sign of SSH anomaly starting from the end of 1996 and continuing up to 2002 be attributed to teleconnection patterns? Previous studies have revealed that interannual fluctuations in various properties of the North Atlantic and the adjacent European shelf are connected to the various climate indices, such as the North Atlantic Oscillation (NAO), known to be the dominant mode of variability of the Northern Hemisphere atmospheric circulation (e.g., Molinero et al. 2005).

Here we use three indices that are previously shown to have influences on climatic variations of various oceanic parameters in the Black Sea (e.g., Hurrell et al. 2003): NAO, East Atlantic (EA) pattern, and East Atlantic/West Russia (EA/ WR) pattern. All of these standardized amplitudes of monthly Northern Hemisphere teleconnection indices are obtained from the Climate Prediction Center Web page (http://www.cpc.ncep.noaa.gov/data/teledoc/telecontents.shtml), which also provides techniques used for calculating them. Description of the above-mentioned indices can be found in Barnston and Livezey (Barnston and Livezey 1987).

We seek whether there is any relationship between the basin-averaged monthly mean SSH values (Figure 2) and teleconnection patterns (NAO, EA, and EA/WR) to determine whether the shift in the SSH anomalies may be attributed to changes in climate indices. Correlations were calculated for each year, separately (Figure 4). The reason of using time series of 12 monthly values for SSH and climate indices for the correlation calculation in each year is to investigate whether the shift to the positive mode of SSH starting from the end of 1996 is specifically controlled by any large-scale atmospheric teleconnection patterns.

Correlation values reveal dependence of SSH anomaly on NAO only from 1996 through 2002. A value of at least \pm 0.53 is needed for a correlation to be statistically significant in comparison to zero correlation at the $95 \%(\alpha=0.05)$ confidence level based on 12 monthly mean time series for a given year. Monthly mean SSH anomalies are strongly related to NAO with statistically significant correlation values of $0.65,0.81,0.74$, and -0.80 in 1997, 1998, 2000, and 2002. In addition to NAO, there are also significant correlations for EA and EA/WR for much of the period of 1996-2002, which also corresponds to the positive SSH mode. In other years, correlations with climate indices are generally mixed between positive and negative values. Thus, the possible role of the large-scale atmospheric changes in influencing monthly SSH anomalies cannot be neglected in the Black Sea. If these three indices are correlated, then the Black Sea SSH anomalies are strongly related to them as well.

\section{Conclusions}

All available altimeter data were used to produce $1 / 4^{\circ} \times 1 / 4^{\circ}$ resolution daily SSH fields from 1993 through 2005 over the Black Sea. An analysis of these fields 
Earth Interactions - Volume 12 (2008) - Paper No. 10 • Page 10

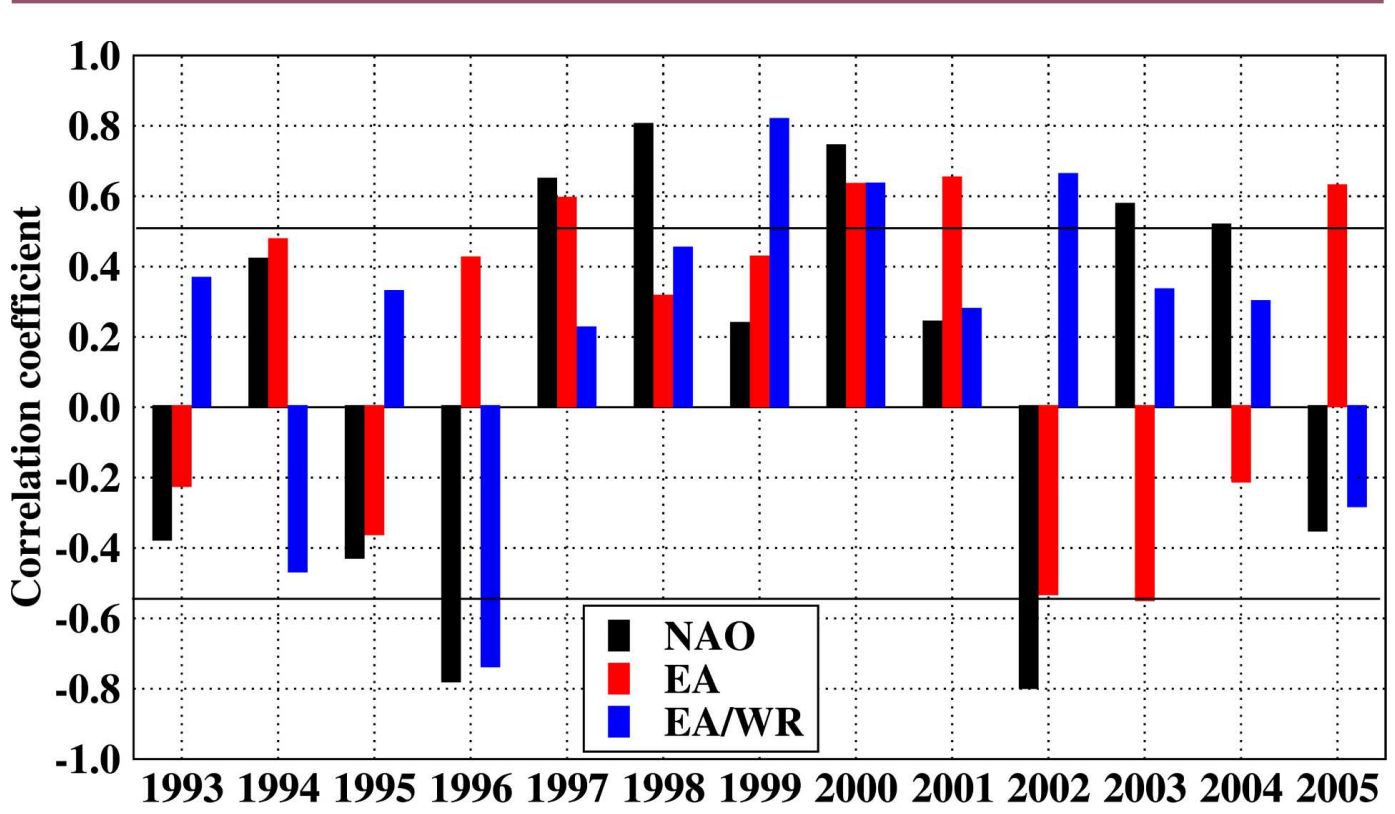

Figure 4. Linear correlation coefficients between the SSH anomaly and climate indices (NAO, EA, EA/WR) calculated over the annual cycle. Horizontal lines show if any correlation value is statistically different than a correlation value of zero.

reveals cyclic variations on multiyear and shorter time scales. The anomalies from the interannual SSH cycle are found to be correlated with similarly formed SST anomalies only in winter. Since the mixed layer is relatively deep in winter, an SST anomaly would correspond to a thermal expansion or contraction averaged over the mixed layer, and thus a proportionally large fraction of the steric anomaly in SSH. The lack of relationship in other seasons indicates that SSH and SST together provide independent information on the state and response of the Black Sea.

We demonstrate that while sea level variations are caused by the local factors, such as steric variations due to the heat and salt exchanges between the atmosphere and ocean, the internal ocean dynamics, tidal currents, and wave propagation, etc., the influence of teleconnection patterns cannot be neglected. In particular, climatic variability in the SSH anomaly are found to be related with the climate indices during the SSH shift mode of 1997-2002. Therefore, some of the overall variations in the SSH anomalies can be attributed to large-scale atmospheric events over the Black Sea during periods when the indices are correlated.

Acknowledgments. This work is funded by the Office of Naval Research (ONR) under the 6.1 project, Global Remote Littoral Forcing via Deep Water Pathways. T. Oguz's participation is supported in parts by the EU SESAME and TUBITAK projects. This paper is Contribution NRL/JA/7320/08/8197 and has been approved for public release.

\section{References}

Barnston, A. G., and R. E. Livezey, 1987: Classification, seasonality and persistence of lowfrequency atmospheric circulation patterns. Mon. Wea. Rev., 115, 1083-1126. 


\section{Earth Interactions • Volume 12 (2008) • Paper No. 10 • Page 11}

Barron, C. N., and A. B. Kara, 2006: Satellite-based daily SSTs over the global ocean. Geophys. Res. Lett., 33, L15603, doi:10.1029/2006GL026356.

Hurrell, J. W., Y. Kushnir, G. Ottersen, and M. Visbeck, 2003: An overview of the North Atlantic Oscillation. The North Atlantic Oscillation: Climatic Significance and Environmental Impact, Geophys. Monogr., Vol. 134, Amer. Geophys. Union, 1-36.

Jacobs, G. A., C. N. Barron, D. N. Fox, K. R. Whitmer, S. Klingenberger, D. May, and J. P. Blaha, 2002: Operational altimeter sea level products. Oceanography, 15, 13-21.

Kara, A. B., A. J. Wallcraft, and H. E. Hurlburt, 2005: How does solar attenuation depth affect the ocean mixed layer? Water turbidity and atmospheric forcing impacts on the simulation of seasonal mixed layer variability in the turbid Black Sea. J. Climate, 18, 389-409.

Korotaev, G., T. Oguz, A. Nikiforov, and C. Koblinsky, 2003: Seasonal, interannual, and mesoscale variability of the Black Sea upper layer circulation derived from altimeter data. $J$. Geophys. Res., 108, 3122, doi:10.1029/2002JC001508.

Locarnini, R. A., A. V. Mishonov, J. I. Antonov, T. P. Boyer, and H. E. Garcia, 2006: Temperature. Vol. 1, World Ocean Atlas 2005, NOAA Atlas NESDIS 61, 182 pp.

Mayer, D. A., R. L. Molinari, M. O. N. Baringer, and G. J. Goni, 2001: Transition regions and their role in the relationship between sea surface height and subsurface temperature structure in the Atlantic Ocean. Geophys. Res. Lett., 28, 3943-3946.

Molinero, J. C., F. Ibanez, S. Souissi, M. Chifflet, and P. Nival, 2005: Phenological changes in the northwestern Mediterranean copepods Centropages typicus and Temora stylifera linked to climate forcing. Oecologia, 145, 640-649.

Oguz, T., and D. Gilbert, 2007: Abrupt transitions of the top-down controlled Black Sea pelagic ecosystem during 1960-2000: Evidence for regime shifts under strong fishery exploitation and nutrient enrichment modulated by climate-induced variations. Deep-Sea Res. I, 54, 220-242.

— J. W. Dippner, and Z. Kaymaz, 2006: Climatic regulation of the Black Sea hydrometeorological and ecological properties at interannual-to-decadal time scales. J. Mar. Syst., 60, 235-254.

Zlotnicki, V., L. L. Fu, and W. Patzert, 1989: Seasonal variability in global sea-level observed with Geosat altimetry. J. Geophys. Res., 94, 17 959-17969.

Earth Interactions is published jointly by the American Meteorological Society, the American Geophysical Union, and the Association of American Geographers. Permission to use figures, tables, and brief excerpts from this journal in scientific and educational works is hereby granted provided that the source is acknowledged. Any use of material in this journal that is determined to be "fair use" under Section 107 or that satisfies the conditions specified in Section 108 of the U.S. Copyright Law (17 USC, as revised by P.IL. 94-553) does not require the publishers' permission. For permission for any other form of copying, contact one of the copublishing societies. 